\title{
Early childhood bilingualism: effects on brain structure and
}

\section{function [version 1; peer review: 2 approved]}

\author{
Sezgi Goksan (iD1,2*, Froso Argyri1* , Jonathan D. Clayden(iD2, Frederique Liegeois², \\ Li Wei ${ }^{1}$
}

${ }^{1}$ Centre for Applied Linguistics, UCL Institute of Education, 20 Bedford Way, London, WC1H OAL, UK

2Developmental Neurosciences Research and Teaching Department, UCL Great Ormond Street Institute of Child Health, 30 Guilford Street, London, WC1N 1EH, UK

${ }^{*}$ Equal contributors

V1 First published: 15 May 2020, 9:370

https://doi.org/10.12688/f1000research.23216.1

Latest published: 04 Nov 2020, 9:370

https://doi.org/10.12688/f1000research.23216.2

\section{Abstract}

Growing up in a bilingual environment is becoming increasingly common. Yet, we know little about how this enriched language environment influences the connectivity of children's brains. Behavioural research in children and adults has shown that bilingualism experience may boost executive control (EC) skills, such as inhibitory control and attention. Moreover, increased structural and functional (resting-state) connectivity in language-related and ECrelated brain networks is associated with increased executive control in bilingual adults. However, how bilingualism factors alter brain connectivity early in brain development remains poorly understood. We will combine standardised tests of attention with structural and resting-state functional magnetic resonance imaging (MRI) in bilingual children. This study will allow us to address an important field of inquiry within linguistics and developmental cognitive neuroscience by examining the following questions: Does bilingual experience modulate connectivity in language-related and EC-related networks in children? Do differences in resting-state brain connectivity correlate with differences in EC skills (specifically attention skills)? How do bilingualism-related factors, such as age of exposure to two languages, language usage and proficiency, modulate brain connectivity?

We will collect structural and functional MRI, and quantitative measures of EC and language skills from two groups of English-Greek bilingual children - 20 simultaneous bilinguals (exposure to both languages from birth) and 20 successive bilinguals (exposure to English between the ages of 3 and 5 years) - and 20 English monolingual children, 8-10 years old. We will compare connectivity measures and attention skills between monolinguals and bilinguals to examine the effects of bilingual exposure. We will also examine to what extent bilingualism factors predict brain connectivity in EC and

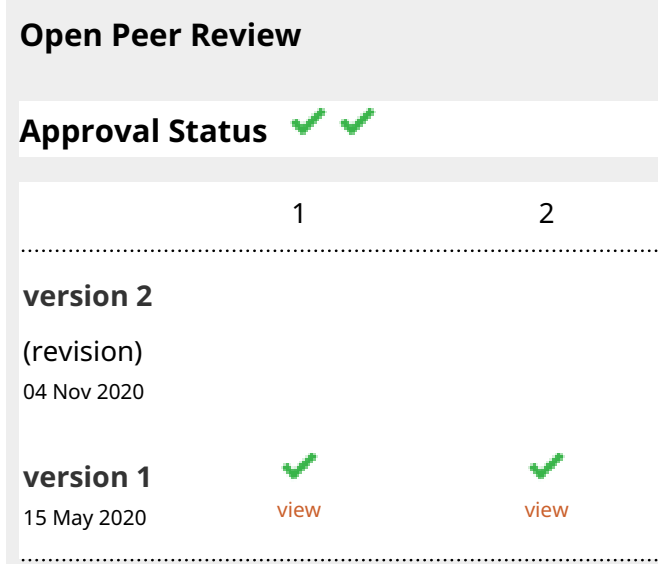

1. Christos Pliatsikas , University of Reading, Reading, UK

2. Manuel Blesa Cábez, The University of Edinburgh, Edinburgh, UK

Paola Galdi, The University of Edinburgh, Edinburgh, UK

Any reports and responses or comments on the article can be found at the end of the article. 
language networks.

Overall, we hypothesize that connectivity and EC will be enhanced in

bilingual children compared to monolingual children, and each

outcome will be modulated by age of exposure to two languages and

by bilingual language usage.

Keywords

Bilingual, children, brain, MRI, language, executive control.

\section{AICI}

This article is included in the UCL Child Health

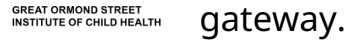

Corresponding authors: Sezgi Goksan (s.goksan@ucl.ac.uk), Froso Argyri (f.argyri@ucl.ac.uk)

Author roles: Goksan S: Data Curation, Formal Analysis, Investigation, Project Administration, Writing - Original Draft Preparation, Writing - Review \& Editing; Argyri F: Conceptualization, Data Curation, Formal Analysis, Funding Acquisition, Investigation, Project Administration, Writing - Original Draft Preparation, Writing - Review \& Editing; Clayden JD: Conceptualization, Funding Acquisition, Supervision, Writing - Review \& Editing; Liegeois F: Conceptualization, Funding Acquisition, Supervision, Writing - Review \& Editing; Wei L: Conceptualization, Funding Acquisition, Project Administration, Supervision, Writing - Review \& Editing

Competing interests: No competing interests were disclosed.

Grant information: This project is funded by The Leverhulme Trust (Grant reference: RPG-2017-403).

The funders had no role in study design, data collection and analysis, decision to publish, or preparation of the manuscript.

Copyright: (c) 2020 Goksan S et al. This is an open access article distributed under the terms of the Creative Commons Attribution License, which permits unrestricted use, distribution, and reproduction in any medium, provided the original work is properly cited.

How to cite this article: Goksan S, Argyri F, Clayden JD et al. Early childhood bilingualism: effects on brain structure and function [version 1; peer review: 2 approved] F1000Research 2020, 9:370 https://doi.org/10.12688/f1000research.23216.1

First published: 15 May 2020, 9:370 https://doi.org/10.12688/f1000research.23216.1 


\section{Introduction}

Early life experiences shape brain and cognitive development ${ }^{1,2}$. The study of bilingualism provides a unique model to examine the neural changes linked to early experiences, i.e. whether there are early bilingual language experience effects on the brain, since two languages can be acquired from birth or one language can be acquired from birth and a second language later in life $^{3-5}$. Despite there being a greater number of multilingual adults in Europe compared with monolinguals ${ }^{6}$, the effect of early bilingual language exposure on brain structure and function is still poorly understood ${ }^{4}$. Crucially, most research has focused on adults (see 7 for a review), after decades of bilingualism exposure, alongside other experiences, making it increasingly difficult to associate changes in brain networks with specific experience-related factors.

Our study addresses the following question: Are brain connectivity changes in bilingual children mainly driven by (i) brain maturation stage at age of exposure to two languages, or by (ii) experience-related factors, for example, frequency of use of both languages?

A wide body of research suggests that bilingualism confers advantages in executive control (EC), i.e. the ability to control attention, to inhibit distractions and to shift between goals (e.g. 8, but see 9 for an opposing view). It is hypothesized that this "bilingual advantage" is linked to the ongoing need to manage two language systems, for which EC is required ${ }^{3}$. Brain networks involved in supporting or engaging EC include the fronto-parietal control network (FCN), salience network (SLN) and default mode network (DMN) ${ }^{10}$, used for attending, switching/inhibitory control and disengaging in response to external stimuli, respectively ${ }^{11-14}$. In short, early bilingualism in combination with regular practice of two languages may be associated with better performance on some EC tasks, as well as increased connectivity between EC-related brain networks, because of increased time spent using and controlling two language systems $^{15,16}$.

Although there are a growing number of functional magnetic resonance imaging (MRI) studies investigating the impact of bilingualism on brain activity during executive function tasks (for example 17,18, in adults and 19 in children), there are very few studies on the effects of bilingualism on resting brain networks known to be related to executive function ${ }^{20}$. Specifically, few studies have asked whether bilingual experience modifies resting-state brain networks, such as (i) the FCN (which includes dorsolateral frontal regions and the inferior/superior parietal lobules), (ii) the SLN (which includes the anterior insula and the dorsal anterior cingulate gyrus), and (iii) the DMN (which includes the posterior cingulate gyrus, the ventromedial prefrontal cortex (vmPFC) and the inferior parietal lobule/angular gyri) ${ }^{10,20-27}$. An investigation addressing this question in bilingual adults found there was greater negative correlation between the vmPFC (part of the DMN) and the dorsolateral prefrontal cortex (part of FCN) in simultaneous vs. sequential bilinguals $^{27}$. Moreover the stronger this interaction, the quicker bilinguals responded during "interference suppression" trials in a cognitive control (i.e. Simon) task ${ }^{27}$. Of note, no monolingual adult control group was included in the study. Our study will allow us to disentangle brain alterations in domain-general (EC) vs. in language-specific networks in bilingual and monolingual children.

Additionally, bilingualism factors such as age of exposure to two languages, language usage and proficiency have been shown to impact differences in functional brain activity and connectivity ${ }^{28,29}$. One study has reported that earlier age of acquisition of two languages was associated with stronger functional connectivity between the left inferior frontal gyrus pars triangularis (IFGpt, i.e. Broca's area, BA 45) and its right homolog and with the right inferior parietal lobule (IPL, part of the FCN) ${ }^{4}$. A more recent study also found the same relationship in the bilateral IFG in a different group of highly proficient bilingual adults $^{30}$. Furthermore, the authors observed that greater 'diversity of language use' (i.e. an environment in which both languages are commonly utilised and segregated use of each language is not routine) was positively correlated with functional connectivity between cortical and subcortical brain regions (namely between the anterior cingulate cortex and left putamen, and the left caudate and bilateral superior temporal gyrus (STG) $)^{30}$. Altogether, there is emerging evidence that bilingualism factors influence brain functional connectivity, yet little is known about how these connectivity alterations are related to EC performance.

There is also growing evidence that bilingualism alters the grey and white matter structure in the brain. For example, in adult studies, greater volume and grey matter density are found in regions associated with language, such as the bilateral IFG, IPL, anterior cingulate cortex, caudate and putamen ${ }^{31-35}$ However, a recent study in pre-school children (aged between 3 and 5 years) found evidence of greater functional connectivity in bilinguals than monolinguals but no structural differences in the IFG, thus suggesting that structural changes may only appear after prolonged exposure to two languages ${ }^{36}$.

Diffusion-weighted MRI studies have revealed white matter alterations associated with bilingualism (for example, see 37 for a recent review), as measured by indices related to structural connectivity such as Fractional Anisotropy (FA) ${ }^{38}$. Increased FA in language-specific white matter tracts, such as the inferior fronto-occipital fasciculus (IFOF) has been reported in both adults $^{39}$ and children (aged between 8 and 11 years old) ${ }^{40}$. Mohades and colleagues (2012) showed that simultaneous bilingual children (who had exposure to both language before 3 years old) had greater FA within the IFOF compared to successive bilingual children (where age of exposure to two languages was between 3 and 5 years) ${ }^{40}$. As most MRI studies have focused on adults, it is difficult to disentangle the effects of early environmental changes from those of decades of exposure to bilingualism and other experiences.

In order to disentangle the effects of bilingualism factors and maturational factors on connectivity, we will recruit bilingual children with either early or later (3 to 5 years) age of onset of 
exposure to two languages and extensively characterise their linguistic experience.

The effects of bilingualism on brain structural and functional connectivity can be observed as soon as most EC skills are well developed. We will recruit bilingual children aged $8-10$ years old because this is before the time of significant brain changes related to puberty, yet an age when EC skills are well developed ${ }^{41}$.

\section{Objectives}

Our overall aim is to investigate whether bilingual experience alters EC- and language-related brain networks in children using advanced MRI methods.

Specifically, we will

(i) examine whether structural and functional connectivity at rest ('connectivity' hereafter) differs between two groups of bilingual children and one group of monolingual children;

(ii) identify how age of onset of exposure to two languages, language usage, and proficiency in two languages modulates brain connectivity.

\section{Hypotheses and predictions}

(1) Bilinguals vs. Monolinguals. Early bilingualism will affect connectivity in specific executive control (EC) networks that have been implicated in the ability to engage EC. Both bilingual groups will have stronger functional connectivity within the FCN and DMN networks than monolinguals (as seen for adults in 10).

(2) Simultaneous vs. Successive Bilinguals. The effect of bilingualism on language and EC connectivity will be moderated by age of onset of exposure to two languages. Specifically, the bilingual simultaneous group will show enhanced FCN connectivity relative to the successive bilingual group (as seen for adults in 4).

(3) Within the bilingual groups, language usage and proficiency will moderate the effect of bilingualism on (i) the language network and (ii) the EC network involved in inhibition, i.e. the $\mathrm{SLN}^{14}$, as seen behaviourally ${ }^{15}$. Therefore, we predict a positive correlation between proficiency/usage of both languages and connectivity within the SLN network, and within the language network, across bilingual participants.

\section{Protocol}

Participants

Inclusion criteria. Three groups of typically developing monolingual and bilingual children aged between 8 and 10 years of age will be recruited.

Group 1: English monolingual children, who have exclusively been exposed to English at home since birth (i.e. they are born to English-speaking parents).
Group 2: English-Greek simultaneous bilingual children, exposed to these two languages from birth.

Group 3: English-Greek successive bilinguals, where exposure to Greek was from birth and exposure to English was between the ages of 3 and 5 years (children are born in Greece and arrived in the UK between the ages of 3 and 5 years).

Exclusion criteria. Children are excluded from the study if they (a) have had regular exposure from a young age to other languages other than English and Greek; (b) if their Greek-speaking parents were born and/or have lived in the UK for most of their lives, and did not migrate from Greece to live in the UK during adulthood; (c) are not in mainstream schooling; (d) have any contraindications for MRI (e.g. have metal implants or braces); (e) have history of hearing impairment and/or have been diagnosed with language learning difficulties; (f) have a confirmed or suspected diagnosis of developmental conditions (e.g. ADHD, autism, dyslexia), neurological conditions (e.g. epilepsy, cerebral palsy), severe chronic medical condition or being born extremely premature (earlier than 33 weeks gestational age); or ( $\mathrm{g}$ ) have non-verbal intelligence below 70 (assessed using Raven's Coloured Progressive Matrices, see Methodology section for more detail).

\section{Ethical approval}

The research project has been approved by the UCL Institute of Education Research Ethics Committee (approval number: 1080). Prior to participation, researchers will obtain written informed consent from one parent/guardian and written informed assent from each child participant.

\section{Methodology}

Procedure. Standardised tests are used to measure the children's linguistic and non-linguistic abilities. The bilingual children's parents are also asked to complete a questionnaire recording detailed information about their child's exposure to each language. Furthermore, all children are invited to take part in an MRI brain scanning session during which structural (anatomical and diffusion-weighted) and functional (resting-state) images are acquired.

Background measures: non-verbal ability and verbal working memory. The Raven's Coloured Progressive Matrices (CPM) test is used to assess the non-verbal ability of the child participants (suitable for use with children aged 4 to 11 years ${ }^{42}$ ). During the task each child is asked to complete a puzzle by choosing the correct missing piece from six options. A total of 36 puzzles are presented so that each participant can obtain a maximum score of 36 (one point for each puzzle). Raw CPM scores are then converted to an age-appropriate normalised score (standard score). Standard scores have mean $=100$ and standard deviation $(\mathrm{SD})=15^{42}$. The lowest and highest scores a child can get are $<60$ or $>140$ respectively. No significant gender differences were found in a large, normative sample reported by Raven et al., and distributed by Pearson Inc. (Girls: mean $=101.44, \mathrm{SD}=15.74$, Boys: mean $=99.31, \mathrm{SD}=15.2^{42}$ ). 
Verbal working memory is assessed using subtests that involve repeating series of numbers forwards and backwards (CELF-4 UK ${ }^{43}$ ). The use of this task is advantageous because it involves minimal linguistic/lexical demand, as children only need to be familiar with digits 1 to 9 . It is also suitable for children aged between 5 and 16 years old. Sequences are presented until the child fails to recall two consecutive sequences. The maximum possible raw score for each task is 16 and 14. Standard scores range from 1 to 19 (mean $=10$, standard deviation $=3$, CELF-4 $\mathrm{UK}^{43}$ ).

Expressive vocabulary. The Raven's Crichton Vocabulary Scales (CVS) test is used to assess verbal ability (suitable for use with children aged 4 to 11 years $^{42}$ ). The CVS is a standardised expressive vocabulary test designed for use with the CPM. It assesses the knowledge of words and is constructed to cover as closely as possible the same age range of intellectual development as the CPM. During the CVS, children are asked to describe the meaning of words in a list ( 80 words). Both English and Greek vocabulary are assessed for bilinguals and only in English for monolinguals. Total raw vocabulary scores are then converted to standard scores (mean $=100$, $\mathrm{SD}=15$ ). No significant gender differences were found within two large, normative samples, distributed by Pearson Inc. (English - Girls: mean $=101.05, \mathrm{SD}=15.14$, Boys: mean $=99.92$, $\mathrm{SD}=15.47$; Greek - Girls: mean $=66.5$, $\mathrm{SD}=43.6$, Boys: mean $=67.0, \mathrm{SD}=41.8^{42}$ ).

Executive control. We also record performance on EC skills, focusing on the selective, sustained and switching components of attention. These are assessed using four subtests from a standardized computer-based test (TEA-Ch $2^{44}$ ).

(1) Attention switching is measured in a subtest that involves sorting four objects according to two defined categories (bags and shoes are sorted for either their colour or whether they pair with a hand or feet).

(2) Selective attention is measured via a subtest of target detection amongst distractors.

Sustained attention is measured by the final two tasks;

(3) Children have to detect target sounds (dog barks) while ignoring distractors (other animal noises) and they must concentrate in order to do this successfully for 15 trials (the final score is weighted for accuracy on all trials).

(4) Each child's reaction time (RT) is measured during a 5 minute test (pressing a button in response to the appearance of a blue blob on the screen).

The composite scores per subtest are calculated as follows: (1) mean RT for switch trials (only correct responses used to calculate the mean), (2) average number of correct responses in two $30 \mathrm{~s}$ trials, (3) mean RT weighted for accuracy, and (4) mean RT. The computer-based TEA-Ch 2 assessment produces a PDF output with composite scores and standard scores (either population-based or education-referenced; mean $=10$, standard deviation $=3$ ) for each subtest. Standard scores range from $1-19$.

Inhibitory control in the form of inhibition of a prepotent response is likely to be invoked during the switching attention task. During this task, participants must ignore goal-irrelevant stimuli (for example whether the object is red or blue) in order to produce a goal-relevant response (i.e. whether the object pairs with a hand or feet). It is of note that the rules in this task are presented in blocks of 5 and the mean reaction time is measured as the average response to the 'switch trials' only, i.e. the first response in each block where the rule has switched from either a red/blue decision to a hand/feet decision or vice versa.

Parental questionnaire on history of language exposure and biographical information. Detailed information on the bilingual children's exposure to the two languages is collected via a structured parental questionnaire (ALEQ Heritage developed by Daskalaki et al., 2019 ${ }^{45}$, based on the Alberta Language Environment Questionnaire (ALEQ) ${ }^{46}$ ). The questionnaire includes questions about family demographics, age and length of exposure to the two languages, the child's and the parents' place of birth, language use among the bilingual child and family members in the home, other contexts of bilingual exposure and use (e.g. extracurricular and literacy activities), time of relocation to the UK, and parents' education levels. Information about the socioeconomic status of the family will be calculated based on years of maternal education.

The original ALEQ was designed to measure the current English language use (input and output) in the bilingual child's environment. The adaptation we use (ALEQ Heritage), however, measures the current Greek language use, and thus the 5-point Likert rating scale has been adapted accordingly. For each question in ALEQ Heritage, the scale is as follows: 0-English always/Greek never, 1-English usually/Greek seldom, 2-English $50 \% /$ Greek $50 \%$, 3-English seldom/Greek usually, 4-English never/Greek always.

For the purposes of the current study we will extract the following outcome measure(s):

\section{Language use at home}

Language use at home is calculated by taking the average of two values: (i) Greek/English input and (ii) Greek/English output. Input and output are generated by inserting the Likert scale scores (in response to selected questions) in to the following formula: sum of scores) / (number of scores $x$ ) (see page 7 of Paradis' ALEQ). Input is measured using questions about how frequently family members speak Greek/English to the child using the 5-point Likert scale discussed above, i.e. from 0 (English always/Greek never) to 4 (English never/ Greek always). Output is measured using questions that explore the frequency with which the child speaks Greek/English to family members at home (on the same $0-4$ scale). Greek input and output scores are then averaged to produce a score for language use at home, ranging from 0 to 1 . This score 
provides a quantitative measure of the amount of English/ Greek input and output the child receives and directs to family members. Higher language use scores $(>0.5)$ indicate a higher relative use of Greek language at home, whereas lower scores $(<0.5)$ indicate a higher relative use of English.

\section{Richness score}

English and Greek richness scores range from 0 to 1 . Each score is a proportion (out of 32) representing English/Greek language use during a range of activities both inside and outside the home. Activities include how frequently English and Greek are used with friends, during literacy activities (e.g. reading books, online language games, etc), and during other extra-curricular activities (e.g. music lessons, sports, etc) on a weekly basis. The calculation of richness scores in the adapted version of the questionnaire that we use differs from the original ALEQ because it includes more questions. The key differences are highlighted here. Firstly, Questions 28 and 31a have been combined and the focus is on how much formal Greek education the child receives. This combined question is included in the calculation of both English and Greek richness scores (rather than only being included for the 'mother tongue' in the original ALEQ, thus adding 4 extra points to the English score). In question 30 more activities have been added such as 'use of Skype', 'use of mobile phone', therefore Greek and English each have a maximum score of 14. In addition, question 32 has been repeated and can be included in the final richness score two further times (4 points per question). This captures more contexts in which children socialize with friends or relatives. Therefore, the total denominator is currently 32 for both English and Greek vs. 16 and 20 respectively in the original ALEQ, (see page 10 of Paradis' ALEQ).

\section{Combined Greek score}

A combined score will be calculated and used to denote Greek language use (range $0-2$ ). The score will be generated by adding together each child's scores for language use at home and Greek richness. The combined score will more accurately represent each child's exposure to and use of Greek in various contexts both inside and outside the home.

Magnetic Resonance Imaging (MRI) scans. Children are scanned on a 3T Magnetom Prisma scanner (Siemens). The MRI scanner is specifically designed to be a child-friendly environment with images of fish on the walls. The scanner room is also equipped with a television screen that can be used to play a movie for children during the acquisition of structural images.

To prepare children for the scanner environment we use a booklet designed for children having an MRI scan at Great Ormond Street Hospital. In addition we create a mock scanning session before each scan where children practice laying still in a toy fabric tunnel while listening to scanner noises. Children can also choose whether to have their parent accompany them and remain in the scanner room for the duration of the scan. Each scanning session lasts approximately 45 minutes. This includes the time taken to set up and settle each participant followed by collection of the structural, diffusion and functional resting state images (total acquisition time approximately $22 \mathrm{~min}$ ).

Data are acquired using a 64 channel head coil. A high-resolution magnetisation prepared rapid gradient echo (MPRAGE) T1-weighted 3D image is acquired for anatomical reference per participant using the following parameters (repetition time $(\mathrm{TR})=2300 \mathrm{~ms}$, echo time $(\mathrm{TE})=2.74 \mathrm{~ms}$, inversion time $=$ $909 \mathrm{~ms}$, flip angle $(\mathrm{FA})=8^{\circ}$, acquisition time $(\mathrm{TA})=5 \mathrm{~min}$ $21 \mathrm{~s}$, field of view $(\mathrm{FOV})=256 \times 256 \mathrm{~mm}$, matrix size $=256 \times 256,240$ slices, $1 \mathrm{~mm}$ isotropic voxels, single shot, slice acquisition $=$ ascending, parallel acquisition technique $($ PAT $)=$ GRAPPA). 3D diffusion-weighted MRI scans are collected using a single-shot multi-shell diffusion MRI sequence. The images are encoded along 60 independent directions with b-values of 1000 and $2200 \mathrm{~s} / \mathrm{mm}^{2}(\mathrm{TR}=3050 \mathrm{~ms}, \mathrm{TE}=60$ $\mathrm{ms}, \mathrm{FA}=90^{\circ}, \mathrm{TA}=7 \min 16 \mathrm{~s}, \mathrm{FOV}=220 \times 220 \mathrm{~mm}$, matrix size $=110 \times 110$, voxel size $=2 \times 2 \times 2 \mathrm{~mm}$, number of contiguous axial slices $=66$, slice thickness $=2 \mathrm{~mm}$, distance factor $=10 \%$, slice acquisition $=$ interleaved, PAT $=$ GRAPPA, multi-band acceleration factor $=2$, fat suppression $=$ on). $\mathrm{We}$ also acquire $13 \mathrm{~b} 0$ images and one reverse phase encoded b0.

Resting-state functional MRI (rs-fMRI) are acquired at the end of the scanning protocol, so children have become comfortable with the scanning environment. During the rs-fMRI scan children are asked to fixate their gaze on a cross. This method has been shown to increase reliability in connectivity metrics ${ }^{47}$. The acquisition parameters for the resting scan are as follows: $\mathrm{T} 2 *$ BOLD-weighted, GRE, EPI readout, FA $=75^{\circ}, \mathrm{TE}$ $=26 \mathrm{~ms}, \mathrm{TR}=1240 \mathrm{~ms}$, TA $=6 \min 18 \mathrm{~s}$, number of measurements $=300$, FOV $=200 \mathrm{~mm}$, multi-band 2, 80×80 in-plane matrix size, $2.5 \mathrm{~mm}$ isotropic voxels, 40 slices, slice thickness = $2.5 \mathrm{~mm}$, distance factor $=20 \%$, slice acquisition $=$ interleaved, fat suppression $=$ on, and with a single-band reference (SBref) image acquired at the start. A field map is also acquired (GRE, 2D, dual echo TE1/TE2 $=10 / 12.46 \mathrm{~ms}$, TR $=1020 \mathrm{~ms}$, $\mathrm{TA}=2 \min 47 \mathrm{~s}, \mathrm{FA}=90^{\circ}, \mathrm{FOV}=200 \mathrm{~mm}$, matrix size $=80 \times$ 80 , voxel size $=2.5 \times 2.5 \mathrm{~mm}, 40$ slices, slice thickness $=2.5 \mathrm{~mm}$, distance factor $=20 \%$, slice acquisition $=$ interleaved).

\section{MRI data analysis}

All data are pseudonymised. High-resolution MRI data has visibly identifiable features of the face removed. Data collected from paediatric participants often requires additional, bespoke consideration; in particular, such data can often contain more motion effects than normal. Therefore, all brain imaging data have visual quality checks to assess the presence of motion artefacts. For the structural and functional data automated quality control descriptors are generated (MRI quality control (MRIQC $\left.{ }^{48}\right)$ ). For the diffusion weighted images, eddy quality control is used (eddy_qc ${ }^{49}$ ). The resulting descriptors will be used to detect excessive motion in relation to the rest of the data. Specific pre-processing pipelines (i.e. a series of analysis steps) are subsequently implemented for the structural, diffusion and resting-state functional MRI images (see Figure 1 and Figure 2, and see https://github.com/sgoksan/ paed_mri_preprocessing for detailed code). 


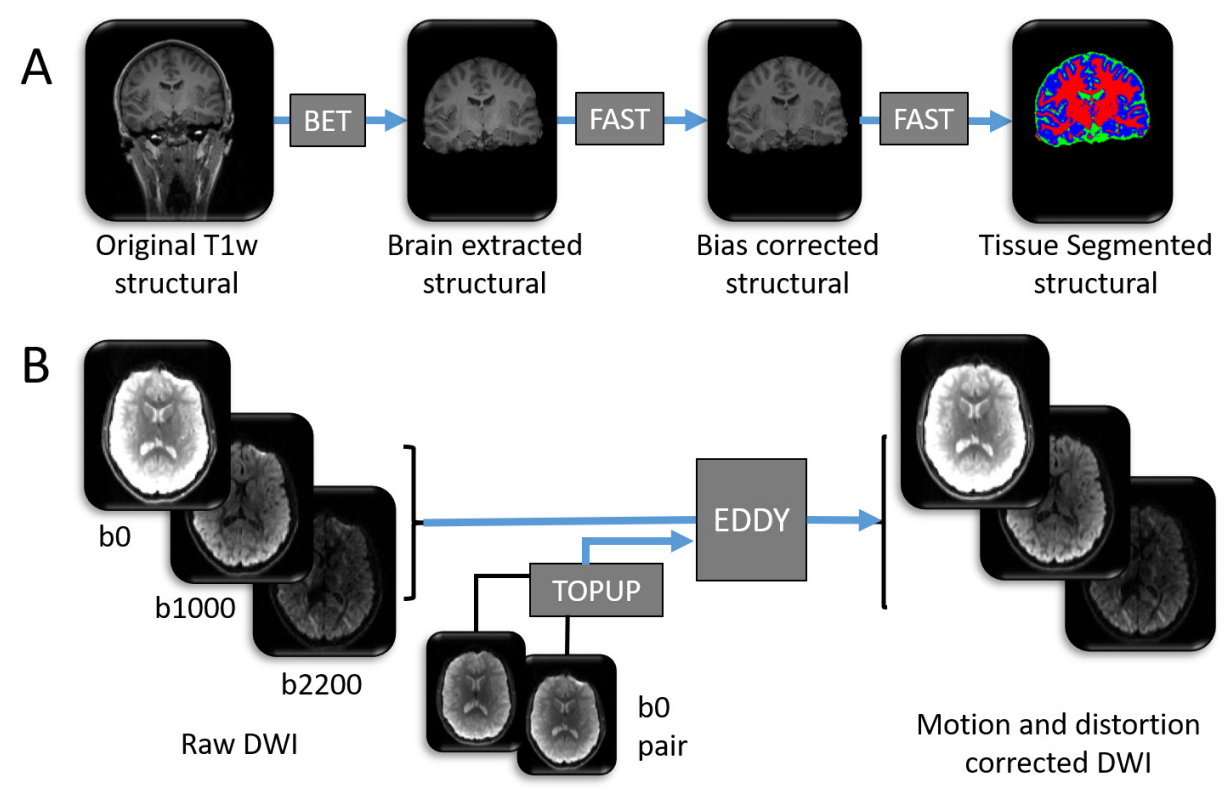

Figure 1. Graphical representation of the structural MRI data analysis pipelines. A summary of the data processing tools used to prepare the (A) T1 weighted image and (B) diffusion weighted image for further analysis. Blue arrows denote pre-processing steps using freely available online tools (named within dark grey boxes). All pictures are of 3 dimensional images from one participant, and represent examples of input and output data files. As part of process (A), each high resolution T1 weighted structural image has (i) non-brain tissue removed using BET, (ii) spatial intensity variations (RF field inhomogeneity) corrected using FAST and (iii) brain tissue types automatically labelled to one of either grey matter, white matter or cerebrospinal fluid (CSF) using FAST. Blue = grey matter, red $=$ white matter, green $=$ CSF. High resolution structural images are shown in greyscale. Note: this figure does not contain all input files and options required for each tool. For a comprehensive list of inputs, see the scripts that accompany this analysis ${ }^{50}$.

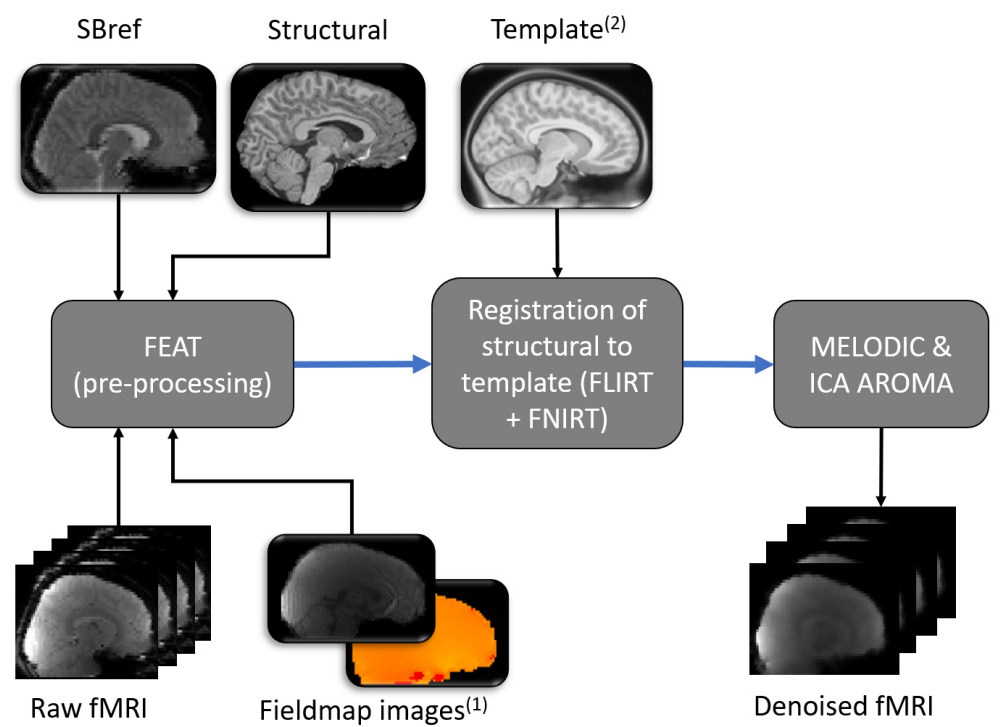

Figure 2. Graphical representation of functional MRI analysis pipeline. Images from one participant represent examples of input and output data files. Blue arrows denote pre-processing steps using freely available online tools (named within dark grey boxes). Pictures with round corners represent 3 dimensional images, while a series of pictures represents 4 dimensional functional data. FEAT was run using the graphical user interface (rather than by running a script), therefore additional required options are detailed within the main text. Subscript numbers highlight steps that were modified in relation to a typical adult pipeline (see Figure 3 for (1) and Figure 4 for (2)). 
As most software has been developed for use with adult data, some aspects of this analysis pipeline have been tailored for a paediatric cohort. These steps included (1) manual editing of fieldmap masks (see Figure 2 and Figure 3), (2) use of a paediatric template brain for registration of structural images (left-right symmetric, created by Fonov et al., using structural images from 112 children, aged $7-11$ years $^{51}$, see Figure 2 and Figure 4), (3) modification of inputs to ICA-AROMA in order to accept a paediatric template and related masks.

MRI data will be analysed using a combination of MRI analysis tools within FMRIB Software Library (FSL) version 6.0.2 $2^{52-54}$ and MRTrix $3^{55}$.

Structural T1. Initial steps on the structural T1-weighted image include brain extraction (i.e. removal of non-brain tissue from the image) using FMRIB's Brain Extraction Tool (BET ${ }^{56,57}$ ), correction of RF inhomogeneity (spatial intensity variations), and segmentation of the different brain tissue types in the T1-weighted structural images using FMRIB's Automated Segmentation Tool (FAST ${ }^{58}$ ) (see Figure 1A).

Diffusion weighted data. For the diffusion weighted structural images, corrections for susceptibility-induced distortions, eddy currents and movements of the head are performed using

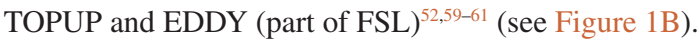

Resting-state functional data. For the functional resting state data, FEAT (Version $6.00^{62}$ ) will be used to run motion correction of the functional data using MCFLIRT ${ }^{63}$, distortion correction using FUGUE, brain extraction using BET $^{64}$ and grand mean scaling ${ }^{62}$. The following images will be prepared for input into FEAT: (1) reference image for motion correction of the functional data and (2) fieldmap and fieldmap magnitude images. A single-band reference (SBref, acquired at the start of the functional scan) will be bias corrected using FAST and then used as an alternative reference image for motion correction. The fieldmap magnitude image will initially have non-brain matter removed using BET and will then be manually edited (see Figure 3). Subsequently, the fsl_prepare_ fieldmap function will be used to create a fieldmap image (for an example see Figure 3). FEAT will also register the SBref to the T1 weighted structural image using FMRIB's linear image registration tool (FLIRT, rigid-body and boundary-based registration) $)^{63,65,66}$. FLIRT and FSL's non-linear image registration tool (FNIRT) are then used to register each participant's structural $\mathrm{T} 1$ weighted image to a Paediatric Template image $^{54}$ (see Figure 4 for example of Paediatric Template). MELODIC (model-free fMRI analysis using probabilistic independent component analysis) will decompose functional data into spatially independent components ${ }^{67}$, which will subsequently automatically be labelled as signal (i.e. not movement) or noise (i.e. motion or physiological artefact) using ICA-AROMA (Automatic Removal of Motion Artifacts ${ }^{68}$ ). ICA components that depict physiological noise or movement are automatically removed (see Figure 5 and Figure 6). Lastly the data is high pass temporal filtered at $0.01 \mathrm{~Hz}(100 \mathrm{~s}$ period).

\section{Statistical plan}

We will compare the brain structural (mean fractional anisotrophy (FA) from DWI-derived tracts of interest) and functional (mean correlation) connectivity in specific networks involved in language and executive control across our three study groups (i.e. simultaneous bilingual, sequential bilingual and monolingual).

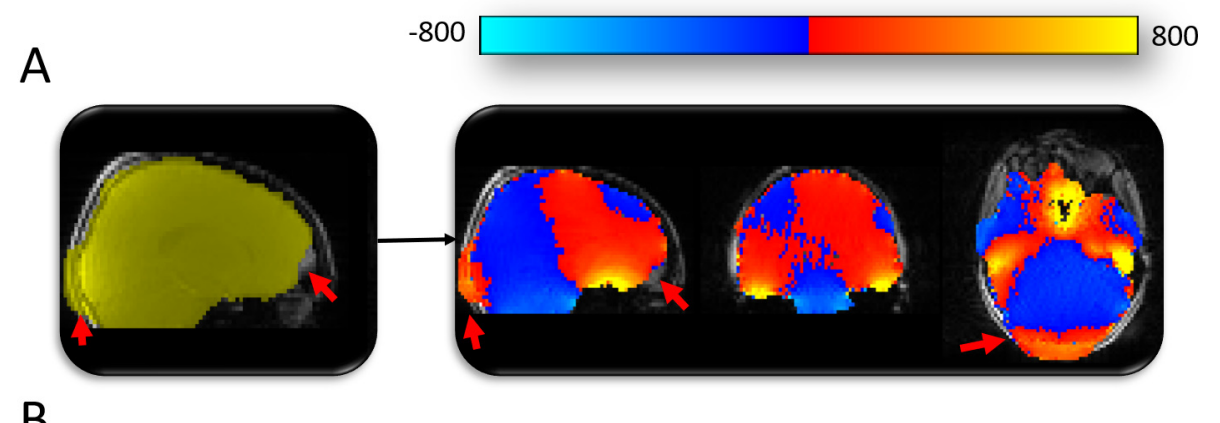

B

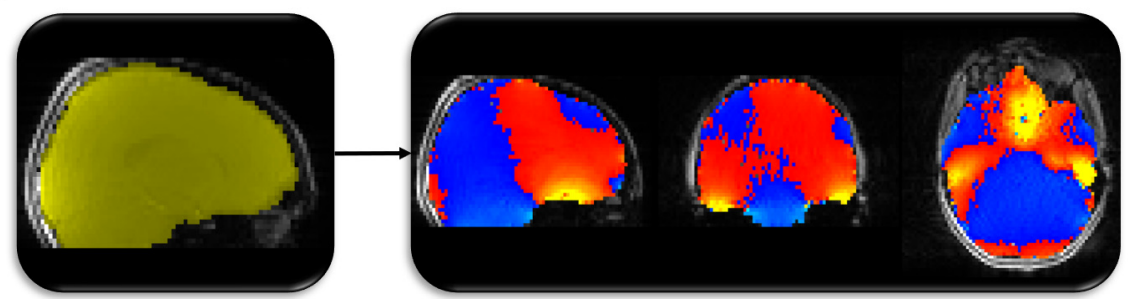

Figure 3. Manual editing of masks for creating fieldmaps. (A) Automated mask generated using BET (shown in yellow). The automated methods used to mask the fieldmap magnitude image were producing sub-optimal results (highlighted by red arrows). Fieldmap image (bluered-yellow image) generated using the sub-optimal mask would leave distortion-susceptible brain regions without appropriate distortion correction (e.g. red arrow in frontal lobe region). (B) Mask following manual editing (yellow) and the subsequent fieldmap (blue-red-yellow) with appropriate coverage of distortion-susceptible regions. 


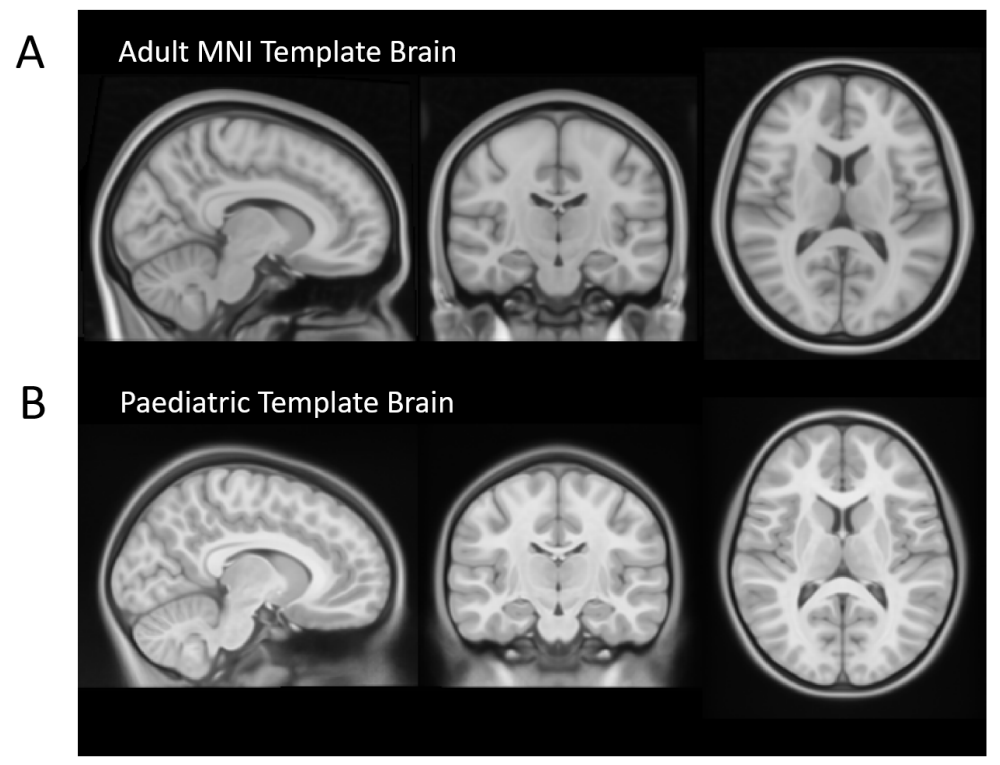

Figure 4. Adult MNI compared with the NIH Paediatric Template Brain. (A) Adult 1mm MNI Template Brain which is commonly used as the standard space image for functional MRI analysis (available as part of FSL). (B) A symmetric paediatric template brain that has been created by Fonov et al., $2011^{51}$, using structural images from 112 children, aged $7-11$ years. Use of an age-appropriate template is important in paediatric studies due to important differences between the brains of adults and children. For example, children have less developed frontal lobes, thinner corpus callosum and smaller ventricles.
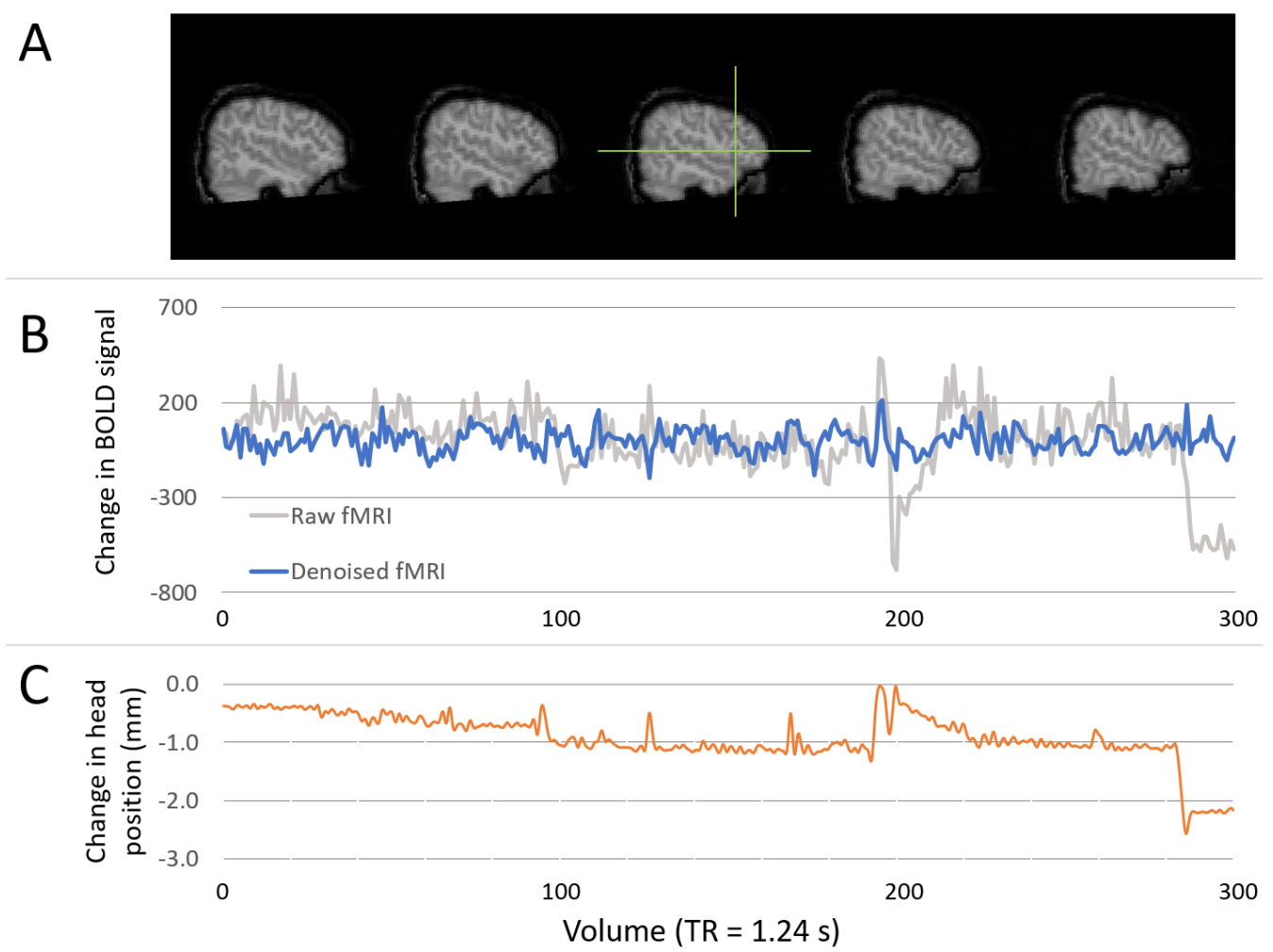

Figure 5. Example of denoising functional data. (A) Images show the location of a chosen voxel (green crosshair), within the left inferior frontal gyrus (pars triangularis). (B) Time series plots showing the change in BOLD signal within the specified voxel for raw data (grey line) and final denoised and temporal filtered data (blue line). All time series are demeaned. Units of change in BOLD are arbitrary scanner units. (C) Plot showing the change in head position (left-right) in millimetres. Changes in head position align with large changes in BOLD signal, which are successfully minimised through denoising (via the use of ICA-AROMA). 
$-3$ $-3$ 3
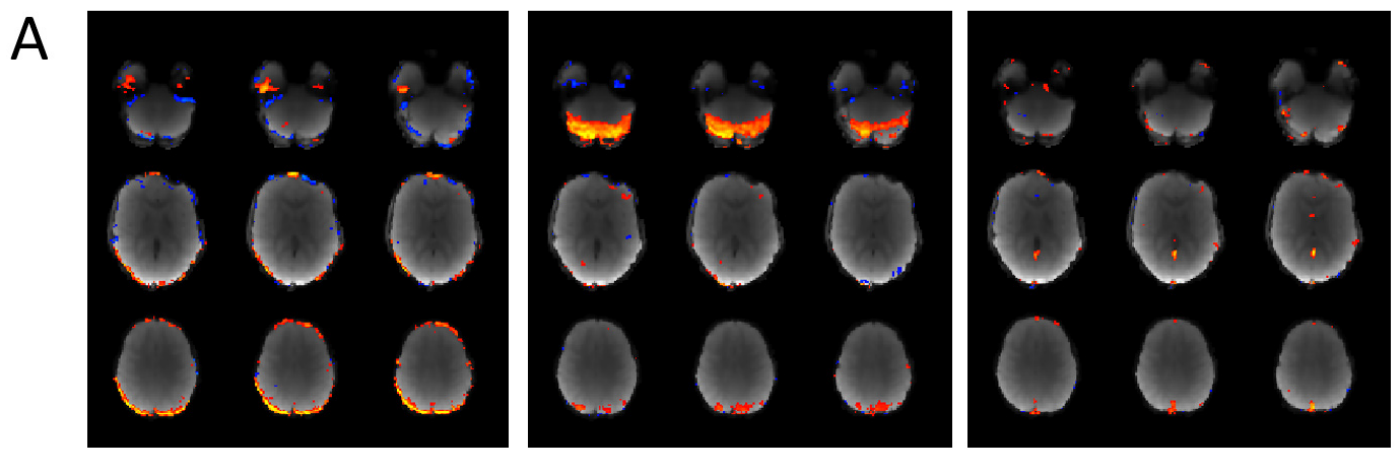

B
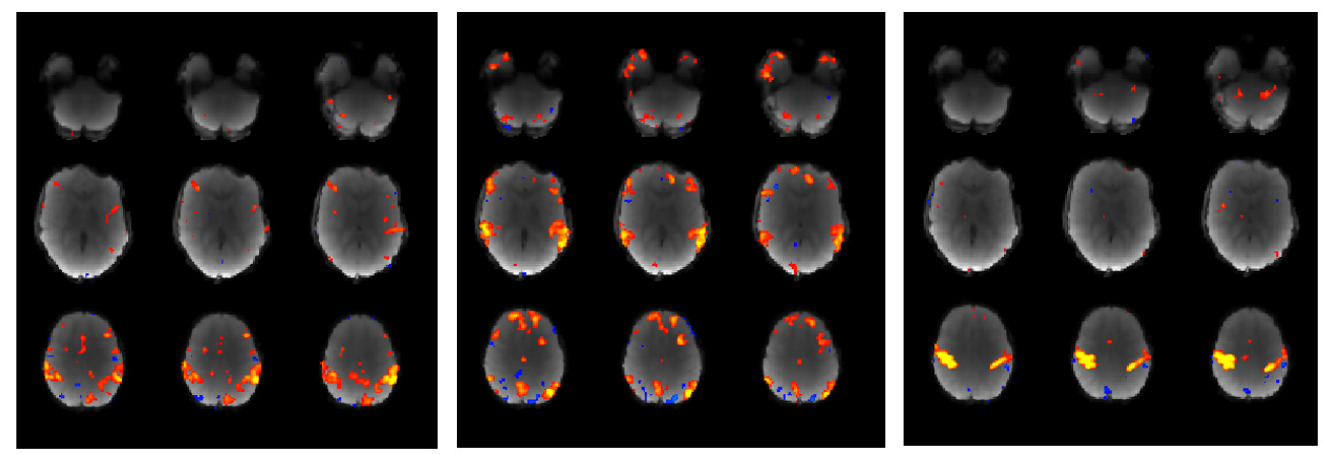

Figure 6. Independent components within a single participant's resting-state fMRI data. Using MELODIC ${ }^{67}$, each individual participant's 4 dimensional $\mathrm{FMRI}$ data is decomposed in to independent spatial and temporal components. ICA-AROMA is then used to (i) automatically identify "movement" components and (ii) remove them from the data ${ }^{68}$. (A) Examples of three separate components labelled as "movement" and subsequently removed from the data. (B) Examples of three separate components that were not labelled as movement and therefore remain within the data.

We will investigate the specificity of differences by also comparing connectivity indices within two networks not hypothesized to be influenced by bilingualism (visual and motor).

Tractography reconstruction. Diffusion data will be prepared for tractography analysis by estimating fibre orientations using multi-shell, multi-tissue, constrained spherical deconvolution ${ }^{69-71}$. Fibre orientation distributions will then be used to calculate mean FA per voxel, as well as run anatomically constrained tractography (ACT), generating streamlines for each tract of interest $^{72}$. The mean FA per tract (weighted by the number of streamlines in each voxel) will then be extracted per participant. The five tracts of interest are two pathways involved in language, one involved in executive control and two control pathways: (a) arcuate fasciculus (dorsal language pathway), (b) inferior fronto-occipital fasciculus (ventral language pathway), (c) fronto-parietal tract (d) optic radiation tract (e) corticospinal tract.

Resting-state network connectivity. In order to investigate functional connectivity, we will extract mean blood oxygen level dependent (BOLD) responses from regions of interest (ROI) in selected resting-state networks. The BOLD responses (i.e. measurements of changes in BOLD signal collected every $1.24 \mathrm{~s}$ for the duration of the functional scan) will be calculated from each pre-defined region of interest (ROI), detailed below. Measurements are collected per voxel and will be averaged across the ROI to create a mean BOLD response across time. Each mean response will be correlated with those within the same network to produce a network-specific correlation matrix per participant. The bilateral ROIs for each network will be as follows:

(a) language network: the IFG and posterior STG

(b) executive control networks:

(i) FCN: middle frontal gyrus (part of the dorsolateral prefrontal cortex) and inferior/superior parietal lobule,

(ii) SLN: anterior insula and anterior cingulate gyrus,

(iii) DMN: posterior cingulate gyrus, vmPFC, and inferior parietal lobule/angular gyrus,

(iv) subcortical control regions: putamen and caudate,

(c) visual network: primary visual cortex and lateral geniculate nucleus in the thalamus 
(d) motor network: the bilateral precentral gyrus (primary motor cortex region) and ventral lateral thalamic nucleus for functional connectivity.

We will use the following statistical methods to test our hypotheses.

(1) To test whether early bilingualism will affect connectivity in EC networks, we will use graph analysis to calculate the global network efficiency within EC networks and compare this across the three groups.

(2) To test whether age of exposure to two languages influences the mean functional connectivity within language and EC-related networks, we will calculate the average of all absolute connectivity values across all the edges within each network and compare this between the three groups using analyses of covariance.

(3) To test whether age of exposure to two languages, Greek language usage and proficiency influences connectivity within language and EC-related networks we will compare the two bilingual groups on both behavioural measures of attention and of brain connectivity (i.e. mean FA and mean functional connectivity) within EC networks. We will use general linear models to examine how much unique variance in connectivity indices is explained by age of exposure to two languages, Greek language usage, and proficiency.

All analyses will include measures of non-verbal ability (CPM scores), working memory (scaled score for total forward and backward digit span) and age at MRI as covariates, where appropriate.

All software that will be used for analysis of the data is open access and therefore freely available online.

\section{Plans for dissemination}

Project findings will initially be disseminated as an open access preprint publication. This will be followed by publication as an original research article in a peer-reviewed journal. We will also share key findings and their implications with educators, policy makers and the wider public. Finally, dissemination to non-academic audiences will be done via public engagement events to schools and parents' networks through UCL BiLingo (Dr Froso Argyri and Prof Li Wei are Co-founders of this service).
Permission is requested from each parent/guardian in order to make their child's anonymised data available online. Where open MRI data is a requirement for publication we will make consented, anonymised data available at that time, otherwise we aim to publish the anonymised MRI imaging data (for which permission was obtained from parents, including for images used in this protocol) on OpenNeuro at the end of the project. MRI data will be organised using the Brain Imaging Data Structure (BIDS) framework.

\section{Study status}

This project is ongoing and we are actively recruiting. Brain imaging and behavioural data has currently been collected from 48 participants.

\section{Conclusion}

This study will quantify how bilingualism and maturational factors impact executive control and brain connectivity in the child brain. We will examine the effect of bilingualism on both domain specific (language) and domain general (EC) networks. As a result, our findings will shed light on the early effects of enriched linguistic environment on brain maturation.

\section{Data availability}

Underlying data

No data is associated with this article.

\section{Extended data}

Custom written scripts that will be used to analyse each set of data are available: https://github.com/sgoksan/paed_mri_ preprocessing

Archived scripts as at time of publication: http://doi.org/ 10.5281 /zenodo. $3778811^{50}$

License: MIT License

\section{Acknowledgements}

We would like to thank Mrs Tina Banks and her team of research radiographers at Great Ormond Street Hospital for providing incredible support and expertise to the project. We also thank Professor Chris Clark for providing integral support and access to the MRI scanner. Finally, we are grateful to all the participants and parents who have volunteered and taken part in this research study. All research at Great Ormond Street Hospital NHS Foundation Trust and the UCL Great Ormond Street Institute of Child Health is made possible by the NIHR Great Ormond Street Hospital Biomedical Research Centre.
1. Neville $\mathrm{H}$, Bavelier D: Human brain plasticity: evidence from sensory deprivation and altered language experience. Prog Brain Res. 2002; 138 177-88.

PubMed Abstract | Publisher Full Text
2. Johnson $\mathrm{MH}$ : Interactive specialization: a domain-general framework for human functional brain development? Dev Cogn Neurosci. 2011; 1(1): 7-21. PubMed Abstract | Publisher Full Text | Free Full Text

3. Bialystok E: The bilingual adaptation: How minds accommodate experience. 
Psychol Bull. 2017; 143(3): 233-262.

PubMed Abstract | Publisher Full Text | Free Full Text

4. Berken JA, Chai X, Chen JK, et al.: Effects of Early and Late Bilingualism on Resting-State Functional Connectivity. J Neurosci. 2016; 36(4): 1165-72. PubMed Abstract | Publisher Full Text | Free Full Text

5. Mohades SG, Van Schuerbeek P, Rosseel Y, et al:: White-matter development is different in bilingual and monolingual children: a longitudinal DTI study. PLOS One. 2015; 10(2): e0117968.

PubMed Abstract | Publisher Full Text | Free Full Text

6. Eurostat: Education and training in the EU. 2016. Reference Source

7. Wong B, Yin B, O'Brien B: Neurolinguistics: Structure, Function, and Connectivity in the Bilingual Brain. Biomed Res Int. 2016; 2016: 7069274 PubMed Abstract | Publisher Full Text | Free Full Text

8. Bialystok E: Bilingualism and the Development of Executive Function: The Role of Attention. Child Dev Perspect. 2015; 9(2): 117-121. PubMed Abstract | Publisher Full Text | Free Full Text

9. Paap KR, Johnson HA, Sawi O: Bilingual advantages in executive functioning either do not exist or are restricted to very specific and undetermined circumstances. Cortex. 2015; 69: 265-78. PubMed Abstract | Publisher Full Text

10. Grady CL, Luk G, Craik FI, et al.: Brain network activity in monolingual and bilingual older adults. Neuropsychologia. 2015; 66: 170-81. PubMed Abstract | Publisher Full Text | Free Full Text

11. Fox MD, Snyder $A Z$, Vincent $\mathrm{JL}$, et al:: The human brain is intrinsically organized into dynamic, anticorrelated functional networks. Proc Natl Acad Sci U S A. 2005; 102(27): 9673-8.

PubMed Abstract | Publisher Full Text | Free Full Text

12. Goulden, N, Khusnulina A, Davis NJ, et al.: The salience network is responsible for switching between the default mode network and the central executive network: replication from DCM. Neuroimage. 2014; 99: 180-90. PubMed Abstract | Publisher Full Text

13. Dosenbach NU, Fair DA, Cohen AL, et al:: A dual-networks architecture of topdown control. Trends Cogn Sci. 2008; 12(3): 99-105. PubMed Abstract | Publisher Full Text | Free Full Text

14. Bonnelle V, Ham TE, Leech R, et al:: Salience network integrity predicts default mode network function after traumatic brain injury. Proc Natl Acad Sci U S A. 2012; 109(12): 4690-5.

PubMed Abstract | Publisher Full Text | Free Full Text

15. Yow WQ, X Li: Balanced bilingualism and early age of second language acquisition as the underlying mechanisms of a bilingual executive control advantage: why variations in bilingual experiences matter. Front Psychol. 2015; 6: 164 .

PubMed Abstract | Publisher Full Text | Free Full Text

16. Green DW, Abutalebi J: Language control in bilinguals: The adaptive control hypothesis. J Cogn Psychol (Hove). 2013; 25(5): 515-530. PubMed Abstract | Publisher Full Text | Free Full Text

17. Garbin G, Sanjuan A, Forn C, et al:: Bridging language and attention: brain basis of the impact of bilingualism on cognitive control. Neuroimage. 2010; 53(4): $1272-8$.

PubMed Abstract | Publisher Full Text

18. Luk G, Anderson JA, Craik Fl, et al:: Distinct neural correlates for two types of inhibition in bilinguals: response inhibition versus interference suppression. Brain Cogn. 2010; 74(3): 347-57.

PubMed Abstract | Publisher Full Tex

19. Mohades SG, Struys E, Van Schuerbeek $P$, et al:: Age of second language acquisition affects nonverbal conflict processing in children: an fMRI study. Brain Behav. 2014; 4(5): 626-42.

PubMed Abstract | Publisher Full Text | Free Full Text

20. Pliatsikas C, Luk G: Executive control in bilinguals: A concise review on fMRI studies. Bilingualism: Language and Cognition. 2016; 19(4): 699-705. Publisher Full Text

21. Vincent JL, Kahn I, Snyder AZ, et al:: Evidence for a frontoparietal control system revealed by intrinsic functional connectivity. J Neurophysiol. 2008; 100(6): 3328-42.

PubMed Abstract | Publisher Full Text | Free Full Text

22. Seeley WW, Menon V, Schatzberg AF, et al:: Dissociable intrinsic connectivity networks for salience processing and executive control. J Neurosci. 2007; 27(9): 2349-56.

PubMed Abstract | Publisher Full Text | Free Full Text

23. Raichle ME, MacLeod AM, Snyder AZ, et al:: A default mode of brain function

Proc Natl Acad Sci U S A. 2001; 98(2): 676-82.

PubMed Abstract | Publisher Full Text | Free Full Text

24. Buckner RL, Andrews-Hanna JR, Schacter DL: The brain's default network: anatomy, function, and relevance to disease. Ann NY Acad Sci. 2008; 1124: $1-38$.

PubMed Abstract | Publisher Full Text

25. Power JD, Cohen AL, Nelson SM, et al.: Functional network organization of the human brain. Neuron. 2011; 72(4): 665-78. PubMed Abstract | Publisher Full Text | Free Full Text

26. Yeo BT, Krienen FM, Sepulcre J, et al:: The organization of the human cerebral cortex estimated by intrinsic functional connectivity. J Neurophysiol. 2011; 106(3): 1125-65.

PubMed Abstract | Publisher Full Text | Free Full Text
27. Kousaie S, Chai XJ, Sander KM, et al:: Simultaneous learning of two languages from birth positively impacts intrinsic functional connectivity and cognitive control. Brain Cogn. 2017; 117: 49-56.

PubMed Abstract | Publisher Full Tex

28. Sulpizio S, Del Maschio N, Del Mauro G, et al.: Bilingualism as a gradient measure modulates functional connectivity of language and control networks. Neuroimage. 2020; 205: 116306

PubMed Abstract | Publisher Full Text

29. Kotz SA: A critical review of ERP and fMRI evidence on $L 2$ syntactic processing. Brain Lang. 2009; 109(2-3): 68-74.

PubMed Abstract | Publisher Full Text

30. Gullifer JW, Chai XJ, Whitford V, et al.: Bilingual experience and resting-state brain connectivity: Impacts of L2 age of acquisition and social diversity of language use on control networks. Neuropsychologia. 2018; 117: 123-134. PubMed Abstract | Publisher Full Text | Free Full Text

31. Mechelli A, Crinion JT, Noppeney U, et al:: Neurolinguistics: structural plasticity in the bilingual brain. Nature. 2004; 431(7010): 757 .

PubMed Abstract | Publisher Full Text

32. Klein D, Mok K, Chen JK, et al:: Age of language learning shapes brain structure: a cortical thickness study of bilingual and monolingual individuals. Brain Lang. 2014; 131: 20-4.

PubMed Abstract | Publisher Full Text

33. Zou L, Ding G, Abutalebi J, et al.: Structural plasticity of the left caudate in bimodal bilinguals. Cortex. 2012; 48(9): 1197-206. PubMed Abstract | Publisher Full Text

34. Abutalebi J, Della Rosa PA, Gonzaga AK, et al:: The role of the left putamen in multilingual language production. Brain Lang. 2013; 125(3): 307-15. PubMed Abstract | Publisher Full Text

35. Abutalebi J, Della Rosa PA, Green DW, et al:: Bilingualism tunes the anterior cingulate cortex for conflict monitoring. Cereb Cortex. 2012; 22(9): 2076-86. PubMed Abstract | Publisher Full Text

36. Thieba C, Long X, Dewey D, et al.: Young children in different linguistic environments: A multimodal neuroimaging study of the inferior frontal gyrus. Brain Cogn. 2019; 134: 71-79.

PubMed Abstract | Publisher Full Text

37. Pliatsikas C: Understanding structural plasticity in the bilingual brain: The Dynamic Restructuring Model. Biling: Lang Cogn. 2020; 23(2): 459-471. Publisher Full Text

38. Beaulieu C: The basis of anisotropic water diffusion in the nervous system - a technical review. NMR Biomed. 2002; 15(7-8): 435-55.

PubMed Abstract | Publisher Full Text

39. Pliatsikas $C$, Moschopoulou E, Saddy JD: The effects of bilingualism on the white matter structure of the brain. Proc Natl Acad Sci U S A. 2015; 112(5): $1334-7$

PubMed Abstract | Publisher Full Text | Free Full Text

40. Mohades SG, Struys E, Van Schuerbeek $P$, et al:: DTI reveals structura differences in white matter tracts between bilingual and monolingual children. Brain Res. 2012; 1435: 72-80.

PubMed Abstract | Publisher Full Tex

41. Anderson VA, Anderson P, Northam E, et al: Development of executive functions through late childhood and adolescence in an Australian sample. Dev Neuropsychol. 2001; 20(1): 385-406. PubMed Abstract | Publisher Full Text

42. Raven Jea: Raven's Progressive Matrices and Vocabulary Scales. Pearson Clinical Assessment. 2008.

43. Semel E, Wiig E, Secord W: Clinical Evaluation of Language Fundamentals. Fourth Edition UK, (CELF4- UK). Pearson, Oxford, UK, 2003. Reference Sourc

44. Manly $\mathrm{T}$, Anderson V, Crawford J, et al:: Test of Everyday Attention for Children, Second Edition (TEA-Ch2). Pearson, Oxford, UK, 2016. Reference Source

45. Daskalaki E, Chondrogianni V, Blom E, et al:: Input effects across domains: The case of Greek subjects in child heritage language. Second Lang Res. 2019; 35(3): 421-445 Publisher Full Text

46. Paradis J: Individual differences in child English second language acquisition: comparing child-internal and child-external factors. Linguist Approaches Biling. 2011; 1(3): 213-237. Publisher Full Text

47. Patriat R, Molloy EK, Meier TB, et al.: The effect of resting condition on restingstate fMRI reliability and consistency: a comparison between resting with eyes open, closed, and fixated. Neuroimage. 2013; 78: 463-73. PubMed Abstract | Publisher Full Text | Free Full Text

48. Esteban O, Birman D, Schaer M, et al.: MRIQC: Advancing the automatic prediction of image quality in MRI from unseen sites. PLOS One. 2017; 12(9): e0184661.

PubMed Abstract | Publisher Full Text | Free Full Text

49. Bastiani M, Cottaar M, Fitzgibbon SP, et al:: Automated quality control for within and between studies diffusion MRI data using a non-parametric framework for movement and distortion correction. Neuroimage. 2019; 184: 801-812. PubMed Abstract | Publisher Full Text | Free Full Text

50. Goksan S: sgoksan/paed_mri_preprocessing: Initial release of scripts (Version v1.0.0). Zenodo. 2020.

http://www.doi.org/10.5281/zenodo.3778811 
51. Fonov V, Evans AC, Botteron $\mathrm{K}$, et al:: Unbiased average age-appropriate atlases for pediatric studies. Neuroimage. 2011; 54(1): 313-27. PubMed Abstract | Publisher Full Text | Free Full Text

52. Smith SM, Jenkinson M, Woolrich MW, et al:: Advances in functional and structural MR image analysis and implementation as FSL. Neuroimage. 2004; 23 Suppl 1: S208-19.

PubMed Abstract | Publisher Full Text

53. Woolrich MW, Jbabdi S, Patenaude B, et al.: Bayesian analysis of neuroimaging data in FSL. Neuroimage. 2009; 45(1 Suppl): S173-86.

PubMed Abstract | Publisher Full Text

54. Jenkinson M, Beckmann CF, Behrens TE, et al.: FSL. Neuroimage. 2012; 62(2): 782-90.

PubMed Abstract | Publisher Full Text

55. Tournier JD, Smith R, Raffelt D, et al:: MRtrix3: A fast, flexible and open software framework for medical image processing and visualisation. Neuroimage. 2019; 202: 116137.

PubMed Abstract | Publisher Full Text

56. Smith SM: Fast robust automated brain extraction. Hum Brain Mapp. 2002 17(3): 143-55

PubMed Abstract | Publisher Full Text

57. Jenkinson M, Pechaud M, Smith S: BET2: MR-based estimation of brain, skull and scalp surfaces. Eleventh Annual Meeting of the Organisation for Human Brain Mapping. 2005

58. Zhang $\mathrm{Y}$, Brady M, Smith S: Segmentation of brain MR images through a hidden Markov random field model and the expectation-maximization algorithm. IEEE Trans Med Imaging. 2001; 20(1): 45-57. PubMed Abstract | Publisher Full Text

59. Andersson JL, Skare S, Ashburner J: How to correct susceptibility distortion in spin-echo echo-planar images: application to diffusion tensor imaging Neuroimage. 2003; 20(2): 870-88. PubMed Abstract | Publisher Full Text

60. Andersson JL, Graham MS, Zsoldos E, et al.: Incorporating outlier detection and replacement into a non-parametric framework for movement and distortion correction of diffusion MR images. Neuroimage. 2016; 141: 556-572. PubMed Abstract | Publisher Full Text

61. Andersson JL, Sotiropoulos SN: An integrated approach to correction fo off-resonance effects and subject movement in diffusion MR imaging. Neuroimage. 2016; 125: 1063-1078.

PubMed Abstract | Publisher Full Text | Free Full Text

62. Woolrich MW, Ripley BD, Brady M, et al.: Temporal autocorrelation in univariate linear modeling of FMRI data. Neuroimage. 2001; 14(6): 1370-86. PubMed Abstract | Publisher Full Text

63. Jenkinson M, Bannister P, Brady M, et al:: Improved optimization for the robust and accurate linear registration and motion correction of brain images.

Neuroimage. 2002; 17(2): 825-41.

PubMed Abstract | Publisher Full Text

64. Smith SM, Zhang $Y$, Jenkinson M, et al:: Accurate, robust, and automated longitudinal and cross-sectional brain change analysis. Neuroimage. 2002; 17(1): 479-89.

PubMed Abstract | Publisher Full Text

65. Greve DN, Fischl B: Accurate and robust brain image alignment using boundary-based registration. Neuroimage. 2009; 48(1): 63-72. PubMed Abstract | Publisher Full Text | Free Full Text

66. Jenkinson M, Smith S: A global optimisation method for robust affine registration of brain images. Med Image Anal. 2001; 5(2): 143-56. PubMed Abstract | Publisher Full Text

67. Beckmann CF, Smith SM: Probabilistic independent component analysis for functional magnetic resonance imaging. IEEE Trans Med Imaging. 2004; 23(2): $137-52$.

PubMed Abstract | Publisher Full Text

68. Pruim RHR, Mennes M, van Rooij D, et al.: ICA-AROMA: A robust ICA-based strategy for removing motion artifacts from fMRI data. Neuroimage. 2015; 112: 267-277

PubMed Abstract | Publisher Full Text

69. Tournier JD, Calamante F, Gadian DG, et al.: Direct estimation of the fiber orientation density function from diffusion-weighted MRI data using spherical deconvolution. Neuroimage. 2004; 23(3): 1176-85. PubMed Abstract | Publisher Full Text

70. Tournier JD, Calamante F, Connelly A: Robust determination of the fibre orientation distribution in diffusion MRI: non-negativity constrained superresolved spherical deconvolution. Neuroimage. 2007; 35(4): 1459-72. PubMed Abstract | Publisher Full Text

71. Jeurissen B, Tournier JD, Dhollander T, et al:: Multi-tissue constrained spherica deconvolution for improved analysis of multi-shell diffusion MRI data. Neuroimage. 2014; 103: 411-426. PubMed Abstract | Publisher Full Text

72. Smith RE, Tournier JD, Calamante F, et al:: Anatomically-constrained tractography: improved diffusion MRI streamlines tractography through effective use of anatomical information. Neuroimage. 2012; 62(3): 1924-38. PubMed Abstract | Publisher Full Text 


\section{Open Peer Review}

\section{Current Peer Review Status:}

\section{Version 1}

Reviewer Report 29 May 2020

https://doi.org/10.5256/f1000research.25631.r63537

(C) 2020 Blesa Cábez $\mathbf{M}$ et al. This is an open access peer review report distributed under the terms of the Creative Commons Attribution License, which permits unrestricted use, distribution, and reproduction in any medium, provided the original work is properly cited.

\section{Manuel Blesa Cábez}

MRC Centre for Reproductive Health, The University of Edinburgh, Edinburgh, UK

\section{Paola Galdi}

MRC Centre for Reproductive Health, The University of Edinburgh, Edinburgh, UK

Overall the presented study is very complete and it will provide meaningful information about how bilingualism alters brain connectivity in early brain development. The presented analysis plan is appropriate to answer the questions they are addressing. The scripts (already uploaded to GitHub) will be an important resource for anyone interested to work with these (or similar) datasets, and the availability of the datasets would be an important contribution to the community, as it will be useful for other researchers investigating the mechanisms that change with bilingualism during early brain development.

The study is very well designed, however, I have some questions/suggestions regarding the processing of the data and the statistical analysis. The FA is generally a good biomarker for brain development, however, it is very difficult to interpret. ${ }^{1}$ As the acquired multi-shell diffusion data permits it, did the authors consider calculating also NODDI maps? ${ }^{2}$ In addition, did the authors consider adding some preprocessing steps like denoising or removal of Gibbs rings artifacts to the diffusion pipeline? $?^{3,4}$

Finally, the authors could provide more details on how they plan to control for confounding effects. One important confounder to take into account is gestational age at birth: in fact, some of the children were born between 33 and 37 weeks, and are therefore late preterm. It is well known that preterm babies have small differences in brain structure compared with term-born babies at term equivalent age, and this should be accounted for. ${ }^{5}$ Then they mention that socioeconomic status will be measured on the basis of maternal education, but they don't specify how this variable will be used in their statistical models. Another potential confounder worth considering is brain size, as it correlates to general intelligence ${ }^{6}$ and it has a known effect on functional connectivity estimates (see e.g. Hänggi et al. ${ }^{7}$ ). Finally, there is a large literature on sex differences in language proficiency in childhood and brain development (see Etchell et al. ${ }^{8}$ for a systematic review). Although the authors report that there were no significant sex differences measured in 
normative samples for some of the scores they adopt, it would be worth clarifying the reasons for excluding this factor from the analysis.

\section{References}

1. Jones DK, Knösche TR, Turner R: White matter integrity, fiber count, and other fallacies: the do's and don'ts of diffusion MRI.Neuroimage. 2013; 73: 239-54 PubMed Abstract | Publisher Full Text 2. Zhang H, Schneider T, Wheeler-Kingshott CA, Alexander DC: NODDI: practical in vivo neurite orientation dispersion and density imaging of the human brain.Neuroimage. 2012; 61 (4): 1000-16 PubMed Abstract | Publisher Full Text

3. Veraart J, Fieremans E, Novikov DS: Diffusion MRI noise mapping using random matrix theory. Magn Reson Med. 76 (5): 1582-1593 PubMed Abstract | Publisher Full Text

4. Kellner E, Dhital B, Kiselev VG, Reisert M: Gibbs-ringing artifact removal based on local subvoxelshifts.Magn Reson Med. 76 (5): 1574-1581 PubMed Abstract | Publisher Full Text

5. Thompson DK, Kelly CE, Chen J, Beare R, et al.: Characterisation of brain volume and microstructure at term-equivalent age in infants born across the gestational age spectrum. Neuroimage Clin. 2019; 21: 101630 PubMed Abstract | Publisher Full Text

6. Pietschnig J, Penke L, Wicherts JM, Zeiler M, et al.: Meta-analysis of associations between human brain volume and intelligence differences: How strong are they and what do they mean?. Neurosci Biobehav Rev. 2015; 57: 411-32 PubMed Abstract | Publisher Full Text

7. Hänggi J, Fövenyi L, Liem F, Meyer M, et al.: The hypothesis of neuronal interconnectivity as a function of brain size-a general organization principle of the human connectome.Front Hum Neurosci. 2014; 8: 915 PubMed Abstract | Publisher Full Text

8. Etchell A, Adhikari A, Weinberg LS, Choo AL, et al.: A systematic literature review of sex differences in childhood language and brain development.Neuropsychologia. 114: 19-31 PubMed Abstract | Publisher Full Text

Is the rationale for, and objectives of, the study clearly described?

Yes

Is the study design appropriate for the research question?

Yes

Are sufficient details of the methods provided to allow replication by others? Yes

Are the datasets clearly presented in a useable and accessible format? Yes

Competing Interests: No competing interests were disclosed.

Reviewer Expertise: Neonatal imaging, diffusion MRI, structural connectome, functional MRI, machine learning and statistical modelling.

We confirm that we have read this submission and believe that we have an appropriate level of expertise to confirm that it is of an acceptable scientific standard. 
Sezgi Goksan, UCL Institute of Education, 20 Bedford Way, London, UK

Dr Manuel Blesa Cábez and Dr Paola Galdi,

On behalf of the authors of this manuscript, we would like to thank you both for your invaluable feedback on our project and in particular for your comments and suggestions regarding our preprocessing and statistical analysis plan. Unfortunately, due to the coronavirus pandemic, all staff employed on this project grant are being placed on furlough. Upon our return, we endeavour to respond to your comments and we intend to provide an updated version of the manuscript alongside our response.

We hope you can forgive the delay and we look forward to continuing this discussion.

Kind regards,

Dr Sezgi Goksan

Competing Interests: No competing interests were disclosed.

Author Response 27 Oct 2020

Sezgi Goksan, UCL Institute of Education, 20 Bedford Way, London, UK

Dear Dr Manuel Blesa Cábez and Dr Paola Galdi,

Thank you for taking the time to review our manuscript. We would like to thank you both for your valuable feedback on our project and specifically, for your comments and suggestions with regards to our pre-processing and statistical analysis plan. We would like to address three points:

"The FA is generally a good biomarker for brain development, however, it is very difficult to interpret. ${ }^{1}$ As the acquired multi-shell diffusion data permits it, did the authors consider calculating also NODDI maps?2"

Thank you for suggesting this additional measure. While the calculation of NODDI maps may provide complementary information regarding the underlying neurite morphology, at present we do not have any specific hypotheses with regards to how intracellular or extracellular neurite volumes would change in the bilingual brain. Similarly, we also do not report any specific hypothesis related to mean diffusivity or radial diffusivity. Given this, we have carefully considered all aforementioned measures and chosen not to include them in our statistical analysis plan.

"did the authors consider adding some pre-processing steps like denoising or removal of Gibbs rings artifacts to the diffusion pipeline?"

In order to address potential participant movement artifacts within our data, we run the latest version of Eddy (a tool within FSL), which simultaneously corrects for eddy currents and gross subject movement (1-3), thus providing some denoising our data. Additional 
steps such as noise removal and Gibbs ringing removal are reported to be beneficial when applied prior to running EDDY (4). While such artefacts have, thus far, not been observed in the visual inspection of our diffusion data, we agree that it is important that we assess the data when finalised and investigate whether further denoising and Gibbs removal improve the quality of the pre-processing. We have acknowledged this by adding new sentences outlining this intention to our revised manuscript (see 'Diffusion weighted data' within the MRI data analysis section). Moreover, we are committed to updating our publicly available scripts in future in order to reflect the final pre-processing pipeline.

Added text, MRI data analysis section, Diffusion weighted data: "In addition, given our paediatric cohort, the final set of diffusion images will be carefully assessed to establish whether further denoising and removal of Gibbs ringing artefacts are required. These steps have been recommended for use in adult studies (4), and are available steps within MRTrix3 $(5,6) . "$

"provide more details on how they plan to control for confounding effects"

For this point we have specifically addressed each of the confounding variables that have been highlighted by the reviewers. Namely, (i) gestational age at birth, (ii) socio-economic status, (iii) brain size and the relationship with general intelligence and (iv) gender.

Firstly, we confirm that we are recording this information from each of our participants. We agree that the influence of these variables on our brain imaging data should be carefully considered and our aim is to balance these variables as best we can within each of our groups. Furthermore, we intend to examine the relationships between all of these measures in order to make an informed decision about whether to include each variable in our analysis of the brain imaging data.

1. Gestational age: we collect each child's gestational age at birth via verbal report from the parent(s). At present none of our participants were born preterm, however, as mentioned we are including all children born $>33$ weeks gestational age (GA) in our study. The majority of longitudinal studies investigating brain-derived measures and cognitive outcomes in preterm-born children have focussed on children born $<33$ weeks GA (for example (7-10)). More recently there has been evidence suggesting that children born late preterm (i.e. 33-36 weeks GA) have higher risk of developing poor cognitive outcomes compared to their term-born peers (11). In addition, as you mention, Thompson and colleagues reported that children born late preterm had (i) larger CSF volumes and (ii) lower FA when compared to a group of term-born infants (12). However, it is not known whether such differences persist later in childhood in late preterm-born children. Therefore, we aim to assess whether the data from any preterm-born children requires individual consideration when running our final analysis. If so, we will include gestational age at birth as a confound in our analysis.

2. Socio-economic status (SES): SES impacts neurocognitive development, thereby influencing executive functions such as attention skills as well as measures of brain 
structure and function (13-16). In order to compare our groups fairly, we intend to match our groups for SES. As part of the Alberta Language Environment Questionnaire (17), number of years of maternal education is recorded as a measure of SES for our participants (see details of Parental Questionnaire in Methodology section). We have not specified any criteria related to SES as part of our recruitment, however in order to recruit groups from similar backgrounds we are signposting throughout our university, at local Greek schools (that provide classes at the weekend) and through inviting children and parents to mention our study to other friends at their schools. Through this approach we hope to minimise differences in SES between groups.

3. Brain size and general intelligence: Brain size is an important factor to consider as it is related to general intelligence and brain-derived measures. This relationship has also been reported in children (18). One of our background measures, the outcome score from a Coloured Progressive Matrices (CPM) task, is included as a measure of general intelligence. We are also able to calculate a measure of brain size by extracting total cortical volume from each participant's structural scan. This will allow us to examine the relationship between these two variables in our sample. We will include CPM scores or total cortical volume as a confound measure in our analyses of structural and functional connectivity in the brain. As such we intend to control for effects associated with general intelligence or brain size.

4. Gender: Etchell et al., argue that sex differences may impact brain development and cognitive outcomes (19). Therefore, it is our intention to balance our groups for this factor. This is an additional goal of our current, ongoing recruitment and we have thus far been able to recruit relatively gender-balanced groups. Moreover, we will examine gender-related effects and use gender as a covariate where appropriate.

Added text (bold), Statistical plan section:

"We will examine our data for effects related to gender, socio-economic status and gestational age at birth. We will subsequently make an informed decision regarding whether to include these factors as covariates in our connectivity analyses. Moreover, all analyses will include measures of brain size (total cortical volume) or non-verbal ability (CPM scores), working memory (scaled score for total forward and backward digit span) and age at MRI as covariates, where appropriate."

\section{References:}

1. Andersson JLR, Sotiropoulos SN. An integrated approach to correction for offresonance effects and subject movement in diffusion MR imaging. NeuroImage. 2016;125: 1063-1078.

2. Andersson JLR, Graham MS, Zsoldos E, Sotiropoulos SN. Incorporating outlier detection and replacement into a non-parametric framework for movement and distortion correction of diffusion MR images. NeuroImage. [Online] 2016;141: 556-572. Available from: doi:10.1016/j.neuroimage.2016.06.058

3. Graham MS, Drobnjak I, Zhang H. Realistic simulation of artefacts in diffusion MRI for validating post-processing correction techniques. NeuroImage. [Online] 2016;125: 1079-1094. Available from: doi:10.1016/j.neuroimage.2015.11.006 
4. Maximov II, Alnaes D, Westlye LT. Towards an optimised processing pipeline for diffusion magnetic resonance imaging data: Effects of artefact corrections on diffusion metrics and their age associations in UK Biobank. Human Brain Mapping. [Online] 2019;40(14): 4146-4162. Available from: doi:10.1002/hbm.24691

5. Cordero-Grande L, Christiaens D, Hutter J, Price AN, Hajnal JV. Complex diffusionweighted image estimation via matrix recovery under general noise models. NeuroImage. [Online] 2019;200: 391-404. Available from: doi:10.1016/j.neuroimage.2019.06.039

6. Kellner E, Dhital B, Kiselev VG, Reisert M. Gibbs-ringing artifact removal based on local subvoxel-shifts. Magnetic Resonance in Medicine. [Online] 2016;76(5): 1574-1581. Available from: doi:10.1002/mrm.26054

7. Johnson S. Cognitive and behavioural outcomes following very preterm birth. Seminars in Fetal \& Neonatal Medicine. [Online] W.B. Saunders; 2007;12(5): 363-373. Available from: doi:10.1016/j.siny.2007.05.004

8. Moore T, Hennessy EM, Myles J, Johnson SJ, Draper ES, Costeloe KL, et al. Neurological and developmental outcome in extremely preterm children born in England in 1995 and 2006: the EPICure studies. BMJ. [Online] British Medical Journal Publishing Group; 2012;345(dec04 3): e7961-e7961. Available from: doi:10.1136/bmj.e7961

9. Ancel P-Y, Goffinet F, Group ATE-2W, Kuhn P, Langer B, Matis J, et al. Survival and Morbidity of Preterm Children Born at 22 Through 34 Weeks' Gestation in France in 2011: Results of the EPIPAGE-2 Cohort Study. JAMA Pediatrics. [Online] American Medical Association; 2015;169(3): 230-238. Available from: doi:10.1001/jamapediatrics.2014.3351 10. Linsell L, Johnson S, Wolke D, O'Reilly H, Morris JK, Kurinczuk JJ, et al. Cognitive trajectories from infancy to early adulthood following birth before 26 weeks of gestation: a prospective, population-based cohort study. Archives of Disease in Childhood. [Online] BM] Publishing Group Ltd; 2018;103(4): 363-370. Available from: doi:10.1136/archdischild-2017313414

11. Woythaler M. Neurodevelopmental outcomes of the late preterm infant. Seminars in Fetal \& Neonatal Medicine. [Online] W.B. Saunders; 2019;24(1): 54-59. Available from: doi:10.1016/j.siny.2018.10.002

12. Thompson DK, Kelly CE, Chen J, Beare R, Alexander B, Seal ML, et al. Characterisation of brain volume and microstructure at term-equivalent age in infants born across the gestational age spectrum. NeuroImage. Clinical. [Online] Elsevier; 2019;21: 101630. Available from: doi:10.1016/j.nicl.2018.101630

13. Hackman DA, Farah MJ, Meaney MJ. Socioeconomic status and the brain: mechanistic insights from human and animal research. Nature Reviews Neuroscience. [Online] Nature Publishing Group; 2010;11(9): 651-659. Available from: doi:10.1038/nrn2897

14. Hackman DA, Gallop R, Evans GW, Farah MJ. Socioeconomic status and executive function: developmental trajectories and mediation. Developmental science. [Online] 2nd ed. John Wiley \& Sons, Ltd; 2015;18(5): 686-702. Available from: doi:10.1111/desc.12246 15. Farah MJ. The Neuroscience of Socioeconomic Status: Correlates, Causes, and Consequences. Neuron. [Online] 2017;96(1): 56-71. Available from:

doi:10.1016/j.neuron.2017.08.034

16. Lawson GM, Hook CJ, Farah MJ. A meta-analysis of the relationship between socioeconomic status and executive function performance among children. Developmental science. [Online] 2018;21(2). Available from: doi:10.1111/desc.12529

17. Paradis J. Individual differences in child English second language acquisition: Comparing child-internal and child-external factors. Hulk A, Marinis T (eds.) Linguistic 
Approaches to Bilingualism. [Online] John Benjamins; 2011;1(3): 213-237. Available from: doi:10.1075/lab.1.3.01 par

18. Thompson DK, Matthews LG, Alexander B, Lee KJ, Kelly CE, Adamson CL, et al. Tracking regional brain growth up to age 13 in children born term and very preterm. Nature communications. [Online] Nature Publishing Group; 2020;11(1): 696-11. Available from: doi:10.1038/s41467-020-14334-9

19. Etchell A, Adhikari A, Weinberg LS, Choo AL, Garnett EO, Chow HM, et al. A systematic literature review of sex differences in childhood language and brain development.

Neuropsychologia. [Online] 2018;114: 19-31. Available from:

doi:10.1016/j.neuropsychologia.2018.04.011

Competing Interests: None

Reviewer Report 27 May 2020

https://doi.org/10.5256/f1000research.25631.r63542

(c) 2020 Pliatsikas C. This is an open access peer review report distributed under the terms of the Creative Commons Attribution License, which permits unrestricted use, distribution, and reproduction in any medium, provided the original work is properly cited.

\section{Christos Pliatsikas}

School of Psychology and Clinical Language Sciences, University of Reading, Reading, UK

This manuscript present the research protocol of a well thought through and designed ongoing study on the effects of bilingualism on the brain structure and function of children. This study fills an important gap in the young but expanding literature on the effects of bilingualism on cognition and the brain, by expanding it to a severely under-researched age-range (young children)crucially, the study is administering comprehensive behavioural and MRI batteries which will help uncover whether and how brain differences between bilingual and monolingual children translate to differences in behaviour.

I found the rationale and objectives of the study clearly described, and the study design is very appropriate, although the use of the entire behavioural battery could have also been addressed with appropriate hypotheses, in order to further strengthen the study. In terms of methods, all three main testing components (demographic and language backgrounds, behavioural experiments tapping language and executive functions and the MRI battery), are appropriate, contemporary, and described in full detail allowing for replication of the study. The adaptations of the MRI data analyses to make them appropriate for a paediatric sample is of particular importance here. Finally, with respect to data analysis, it is not clear to me whether the authors were planning to look at grey matter measures (esp. since their T1 images have sufficient resolution) with methods included in FSL, such as whole-brain VBM and subcortical vertex analysis (FIRST). I would strongly advise that, as it will result in a much needed multi-modal investigation of the developing bilingual brain (e.g. see https://psyarxiv.com/kjq6m for a preprint of our recent work looking at both grey and white matter structure of the developing brain, but not brain 
function at rest (Pliatsikas et al., 202011). In all, this is a well-designed study and its outputs will be more than welcome in the field.

\section{References}

1. Pliatsikas C, Meteyard L, Veríssimo J, Deluca $V$, et al.: The effect of bilingualism on brain development from early childhood to young adulthood. 2020. Publisher Full Text

Is the rationale for, and objectives of, the study clearly described?

Yes

Is the study design appropriate for the research question?

Yes

Are sufficient details of the methods provided to allow replication by others? Yes

Are the datasets clearly presented in a useable and accessible format? Not applicable

Competing Interests: No competing interests were disclosed.

Reviewer Expertise: Bilingualism, experience-dependent neuroplasticity

I confirm that I have read this submission and believe that I have an appropriate level of expertise to confirm that it is of an acceptable scientific standard.

Author Response 09 Jun 2020

Sezgi Goksan, UCL Institute of Education, 20 Bedford Way, London, UK

Dr Christos Pliatsikas,

On behalf of the authors of this manuscript, we would like to thank you for your invaluable feedback on our project. Unfortunately, due to the coronavirus pandemic, all staff employed on this project grant are being placed on furlough. Upon our return, we endeavour to respond to your comments and we intend to provide an updated version of the manuscript alongside our response.

We hope you can forgive the delay and we look forward to continuing this discussion.

Kind regards, Dr Sezgi Goksan.

Competing Interests: No competing interests were disclosed. 
Sezgi Goksan, UCL Institute of Education, 20 Bedford Way, London, UK

Dear Dr Christos Pliatsikas,

Thank you for taking the time to review our manuscript and for your valuable feedback on our project. We would like to address two of your comments:

"I found the rationale and objectives of the study clearly described, and the study design is very appropriate, although the use of the entire behavioural battery could have also been addressed with appropriate hypotheses, in order to further strengthen the study."

With regards to reporting specific hypotheses related to our executive control tests, given the contradictory evidence regarding a 'bilingual advantage' in executive control in adult studies (for example see $(1,2)$ for reviews in favour and (3-5) for reviews arguing against), and the few studies investigating EC in childhood (see reviews from $(6,7)$ ), there is insufficient evidence for us to formulate a specific hypothesis. Instead, we intend to explore the behavioural data alongside the brain imaging data. In doing so, we hope to meaningfully contribute this debate. Furthermore, for our background measures, namely the tests of non-verbal fluid intelligence and verbal working memory, we have included new sentences elaborating on the use of these measures in the current literature (see ' Background measures' within the Methodology section in our revised manuscript).

\section{Added text, Methodology section, Background measures:}

"Fluid intelligence, working memory and controlled attention are related yet separable constructs (8-10). We have therefore chosen to collect measures of non-verbal fluid intelligence and verbal working memory as background variables, as in previous studies that have investigated executive control skills in bilingual children and adults (11-15). Based on Engle et al.'s theory, individual differences in working memory capacity and general intelligence will impact a child's innate ability to control their attention (9). Moreover, it has been observed that greater resting-state connectivity of the precuneus/posterior cingulate with other regions of the default mode network, is positively correlated with working memory performance in adults (16). Therefore, we aim to account for individual variability related to measures of executive control by including scores for working memory and general intelligence as confounding factors in our connectivity analyses."

"with respect to data analysis, it is not clear to me whether the authors were planning to look at grey matter measures".

In this protocol we have chosen to focus specifically on measures of structural and functional connectivity in children, as this is the novel aspect of our study. We have therefore not described plans within for analysis of the cortical structures. However, given that we are collecting high-resolution structural images, this is certainly an avenue that can be explored further in the future as a complementary analysis project in which we would aim to replicate and extend results in the existing published literature $(17,18)$. We are committed to sharing further analysis plans via additional scripts for the pre-processing and analysis of structural data on our github page:

https://github.com/sgoksan/paed_mri_preprocessing 


\section{References}

1. Adesope OO, Lavin T, Thompson T, Ungerleider C. A Systematic Review and MetaAnalysis of the Cognitive Correlates of Bilingualism:. Review of Educational Research. [Online] SAGE PublicationsSage CA: Los Angeles, CA; 2010;80(2): 207-245. Available from: doi:10.3102/0034654310368803

2. Bialystok E. Reshaping the mind: the benefits of bilingualism. Canadian journal of experimental psychology = Revue canadienne de psychologie experimentale. [Online] 2011;65(4): 229-235. Available from: doi:10.1037/a0025406

3. Hilchey MD, Klein RM. Are there bilingual advantages on nonlinguistic interference tasks? Implications for the plasticity of executive control processes. Psychonomic Bulletin \& Review. [Online] Springer-Verlag; 2011;18(4): 625-658. Available from: doi:10.3758/s13423011-0116-7

4. Lehtonen M, Soveri A, Laine A, Järvenpää J, de Bruin A, Antfolk J. Is bilingualism associated with enhanced executive functioning in adults? A meta-analytic review. Psychological bulletin. [Online] 2018;144(4): 394-425. Available from: doi:10.1037/bul0000142 5. Donnelly S, Brooks PJ, Homer BD. Is there a bilingual advantage on interferencecontrol tasks? A multiverse meta-analysis of global reaction time and interference cost. Psychonomic Bulletin \& Review. [Online] Springer US; 2019;26(4): 1122-1147. Available from: doi:10.3758/s13423-019-01567-z

6. Barac R, Bialystok E, Castro DC, Sanchez M. The Cognitive Development of Young Dual Language Learners: A Critical Review. Early childhood research quarterly. [Online] 2014;29(4): 699-714. Available from: doi:10.1016/j.ecresq.2014.02.003

7. Ware AT, Kirkovski M, Lum JAG. Meta-Analysis Reveals a Bilingual Advantage That Is Dependent on Task and Age. Frontiers in Psychology. [Online] Frontiers Media SA; 2020;11: 2076. Available from: doi:10.3389/fpsyg.2020.01458

8. Baddeley AD, Hitch G. Working Memory. Psychology of Learning and Motivation. [Online] Academic Press; 1974;8: 47-89. Available from: doi:10.1016/S0079-7421(08)60452-1 9. Engle RW, Kane MJ, Tuholski SW. Individual differences in working memory capacity and what they tell us about controlled attention, general fluid intelligence, and functions of the prefrontal cortex. 1999. Available from: doi:10.1017/CBO9781139174909.007

10. Miyake A, Friedman NP. The Nature and Organization of Individual Differences in Executive Functions: Four General Conclusions. Current Directions in Psychological Science. [Online] SAGE PublicationsSage CA: Los Angeles, CA; 2012;21(1): 8-14. Available from: doi:10.1177/0963721411429458

11. Namazi M, Thordardottir E. A working memory, not bilingual advantage, in controlled attention. International Journal of Bilingual Education and Bilingualism. [Online] 3rd ed. Taylor \& Francis Group; 2010;13(5): 597-616. Available from: doi:10.1080/13670050.2010.488288 12. Bonifacci P, Giombini L, Bellocchi S, Contento S. Speed of processing, anticipation, inhibition and working memory in bilinguals. Developmental science. [Online] John Wiley \& Sons, Ltd; 2011;14(2): 256-269. Available from: doi:10.1111/j.1467-7687.2010.00974.x 13. Engel de Abreu PMJ. Working memory in multilingual children: is there a bilingual effect? Memory (Hove, England). [Online] 2nd ed. Taylor \& Francis Group; 2011;19(5): 529-537. Available from: doi:10.1080/09658211.2011.590504

14. D'Souza AA, Moradzadeh L, Wiseheart M. Musical training, bilingualism, and executive 
function: working memory and inhibitory control. Cognitive research: principles and implications. [Online] 2nd ed. SpringerOpen; 2018;3(1): 11-18. Available from:

doi:10.1186/s41235-018-0095-6

15. Antón E, Carreiras M, Duñabeitia JA. The impact of bilingualism on executive functions and working memory in young adults. Athanasopoulos P (ed.) Public Library of Science ONE. [Online] Public Library of Science; 2019;14(2): e0206770. Available from: doi:10.1371/journal.pone.0206770

16. Sala-Llonch R, Peña-Gómez C, Arenaza-Urquijo EM, Vidal-Piñeiro D, Bargalló N, Junqué $\mathrm{C}$, et al. Brain connectivity during resting state and subsequent working memory task predicts behavioural performance. Cortex; a journal devoted to the study of the nervous system and behavior. [Online] 2012;48(9): 1187-1196. Available from:

doi:10.1016/j.cortex.2011.07.006

17. Archila-Suerte P, Woods EA, Chiarello C, Hernandez AE. Neuroanatomical profiles of bilingual children. Developmental science. [Online] 2018;21(5): e12654. Available from: doi:10.1111/desc.12654

18. Thieba C, Long X, Dewey D, Lebel C. Young children in different linguistic environments: A multimodal neuroimaging study of the inferior frontal gyrus. Brain and cognition. [Online] 2019;134: 71-79. Available from: doi:10.1016/j.bandc.2018.05.009

Competing Interests: None.

The benefits of publishing with F1000Research:

- Your article is published within days, with no editorial bias

- You can publish traditional articles, null/negative results, case reports, data notes and more

- The peer review process is transparent and collaborative

- Your article is indexed in PubMed after passing peer review

- Dedicated customer support at every stage

For pre-submission enquiries, contact research@f1000.com 